\title{
Heterogeneity of Genetic Parameters for Calving Difficulty in Holstein Heifers in Ireland
}

\author{
J. M. Hickey, ${ }^{\dagger} \nmid \ddagger^{1}$ M. G. Keane, ${ }^{\star}$ D. A. Kenny,† A. R. Cromie,§ P. R. Amer, $\|$ and R. F. Veerkampł \\ *Grange Beef Research Centre, Teagasc, Dunsany, Co. Meath, Ireland \\ †School of Agriculture, Food and Veterinary Medicine, College of Life Sciences, University College Dublin, Belfield, Dublin 4, Ireland \\ $\ddagger$ Animal Breeding and Genomics Centre, Animal Sciences Group, PO Box 65, 8200 AB, Lelystad, the Netherlands \\ §lrish Cattle Breeding Federation, Shinagh House, Bandon, Co. Cork, Ireland \\ |Abacus Biotech Limited, PO Box 5585, Dunedin, New Zealand
}

\begin{abstract}
Calving difficulty is a trait that greatly affects animal welfare, herd profitability, and the amount of labor required by cattle farmers. It is influenced by direct and maternal genetic components. Selection and breeding strategies can optimize the accuracy of genetic evaluations and correctly emphasize calving difficulty in multiple-trait indices provided there are accurate estimates of genetic parameters. In Ireland, large differences exist in the age at which heifers first give birth to calves. The objective of this study was to estimate genetic parameters for calving difficulty in first-parity Holsteins and to determine whether these differed with age of the heifer at calving. Transformed calving difficulty records for 18,798 Holstein heifers, which calved between January 2002 and May 2006, were analyzed using univariate, multitrait, and random regression linear sire-maternal grandsire models. The model that 1) fitted a second-order random regression of dam age at first parity for the direct component, 2) treated the maternal component as a single trait regardless of dam age, and 3) fitted a single residual variance component was optimal. Heritabilities for direct (0.13) and maternal (0.04) calving difficulty were significantly different from zero. These 2 components were moderately negatively correlated (-0.47). Estimates of direct genetic variance and heritability were heterogeneous along the dam age trajectory, decreasing initially with dam age before subsequently increasing. Heritability estimates ranged between 0.11 and 0.37 and were higher for records with younger and older dams at parturition. Genetic correlations between the direct components of calving difficulty decreased from unity to 0.5 with increasing distance between dam ages at parturition. The results of this study indicated that heterogeneity of direct genetic
\end{abstract}

Received October 31, 2006.

Accepted March 31, 2007.

${ }^{1}$ Corresponding author: John.Hickey@wur.nl variance existed for calving difficulty, depending on dam age at first parturition.

Key words: calving difficulty, genetic parameter, heterogeneous variance component

\section{INTRODUCTION}

Calving difficulty is a trait that greatly affects animal welfare and herd profitability because of increased labor and veterinary costs, increased calf mortality, and reduced subsequent fertility and survival of the cow. These problems are particularly pertinent in first-calf heifers (Manfredi et al., 1991; Bennett and Gregory, 2001). Although calving difficulty can be reduced by proper management procedures, such as heifer rearing and feeding during gestation, selection and breeding strategies have been shown to reduce the incidence of this problem in the short and long term (Dekkers, 1994). In Ireland, large differences exist in the ages at which heifers first give birth. Therefore, one strategy to reduce calving difficulty could involve the selective mating of bulls with breeding values that are more favorable with respect to age of the heifer. Accurate estimates of genetic parameters can help to optimize such a breeding program for calving difficulty for Holsteins in Ireland. Calving performance is influenced by direct and maternal components (Philipsson et al., 1979). The direct component is the ability of the calf to be born easily, and the maternal component is the ability of the cow to give birth easily (Meijering, 1986). Genetic parameters for calving difficulty have been estimated in numerous studies (e.g., Weller and Ron, 1992; Wiggans et al., 2003). Sex of the calf (Weller and Gianola, 1989) and parity (Steinbock et al., 2003) have been shown to affect these estimates. Several studies have shown that genetic variance for traits differs across a trajectory, for example, of individual age (Arango et al., 2004) or environment (Calus and Veerkamp, 2003). Groen et al. (1998) suggested that for specific situations, genetic parameters for calving difficulty, across parity, may be influenced by the maturity or age of the dam. The effect 
of dam age at calving within a single parity on the variance components of calving difficulty is not known. Currently, the Irish national genetic evaluation system assumes that the genetic variances are homogeneous along the trajectory of dam age at birth (Olori et al., 2005). The objective of this study was to estimate genetic parameters for calving difficulty in first-parity Holsteins and to determine whether the estimates of genetic (co)variance for calving difficulty differed along the trajectory of age of the dam at parturition.

\section{MATERIALS AND METHODS}

\section{Data}

In January 2002, a new system of measuring calving difficulty was adopted for the recording of calving performance in Ireland. The system divides calving difficulty into 4 ordered categories. Each category is determined according to the amount of assistance applied at calving. The categories are $1,2,3$, and 4 and reflect no assistance, some, major, and veterinary assistance, respectively.

Calving performance records for first-parity heifers, which calved between January 2002 and May 2006, were extracted from the central database of the Irish Cattle Breeding Federation. Sex of the calf, calf date of birth, and date of birth of the dam were known for each record. A total of 55,295 records remained after removing 1) records with missing pedigree information, 2 ) records belonging to $<87.5 \%$ Holstein cows, and 3) records from dams that were not between 600 and 1,100 $d$ of age at parturition. Because of well-established problems involved in correctly estimating a fixed contemporary group effect when contemporary groups contain only extreme categories (Misztal et al., 1989), records from herds in which all calvings were scored as the same value were removed. This reduced the data set to 23,934 animals. Sires and maternal grandsires with fewer than 3 calves represented in the data and all herds in which only one sire or maternal grandsire was represented also had their records removed, as had 8 animals that were born as quadruplets.

Contemporary groups in which the calving event occurred were formed for these data using algorithms outlined by Schmitz et al. (1991) and Crump et al. (1997). This method optimizes the composition of contemporary groups based on calving dates and intervals between consecutive calving dates in a herd (Calus and Veerkamp, 2003). The maximum span of a contemporary group was restricted to $180 \mathrm{~d}$, whereas the minimum number of animals in a contemporary group was restricted to 3 . The final data set that underwent analysis contained 18,798 records.
Calving difficulty was recorded as a discrete trait and a skewed distribution was found in the data, with a low incidence of high scores. Following the system of the national genetic evaluation for calving difficulty in Ireland (Olori et al., 2005), the categories major and veterinary assistance were merged into a single category and the data were then transformed to a linear scale assuming an underlying normal distribution with a mean of 0 and a standard deviation of 1 . The underlying score for each category was derived from the proportions of animals in the national herd recorded in each of the calving difficulty categories. Given the $6 \%$ serious incidence in the national population, the transformed scores were $0,1.86$, and 3.14 for none, some, and serious assistance at calving, respectively. The 1.86 and 3.14 corresponded to differences in means of segments of animals on an underlying scale of a standard normal distribution, first between animals requiring no assistance and slight assistance, and then between animals requiring slight assistance and severe assistance. Estimated breeding values and arithmetic means on the transformed scale were then back-transformed to the average expected value for serious calving difficulty by multiplying them by 11.9 and then adding $6 \%$ to the breeding values. This value of 11.9 is a derived linear regression of the percentage of serious difficult calving on EBV on the underlying score at the population mean for percentage of difficult calving. Adding the $6 \%$ allows the EBV to be interpreted as expected average values.

\section{Statistical Models}

The ASReml software (Gilmour et al., 2006) was used to estimate variance components by fitting mixed linear models to the data. The fixed effects included in each model were contemporary group of calf at birth $(2,341$ levels), type of birth (2 levels, single birth or twin/triplet birth), and sex of calf. Interactions between these effects were tested and found not to be significant. Partial confounding existed between the age of dam effect and the contemporary group effect. Therefore, age of dam was not included as a fixed effect.

\section{Univariate Model}

To estimate variance components for calving difficulty, a univariate sire-maternal grandsire model (model 1) was fitted to the data. This model accounted for both the direct (sire of calf + half maternal grandsire of calf) and maternal (maternal grandsire of calf + half maternal grandsire of dam) components of calving difficulty. The model was 


$$
\begin{aligned}
y=\mu+ & \text { fixed effects }+D_{\text {sire }_{c}}+\frac{1}{2} * D_{m g s_{c}} \\
& +M_{m g s_{c}}+\frac{1}{2} * M_{m g s_{d}}+e
\end{aligned}
$$

where $y$ is a vector of transformed calving difficulty scores with an overall mean of $\mu$, and $D$ and $M$ denote direct and maternal effects, respectively, with subscripts of sire ${ }_{c}, m g s_{c}$, and $m g s_{d}$ representing the sire of the calf, maternal grandsire of the calf, and maternal grandsire of the dam, respectively. The direct and maternal effects were assumed to be normally distributed, with means of $0, \operatorname{var}($ direct $)=1 / 4 \sigma_{\mathrm{d}}^{2}, \operatorname{var}($ maternal $)=$ $1 / 4 \sigma_{\mathrm{m}}^{2}$, and $\operatorname{var}(\mathrm{e})=\mathrm{E}$. This model was fitted with the genetic correlation between the direct and maternal effects either estimated or constrained to zero.

\section{Multitrait Models}

A multitrait model version of the univariate model was fitted that separated each of the direct and maternal components into 4 traits depending on whether the dam was 600 to 724,725 to 849,850 to 974 , or 975 to $1,100 \mathrm{~d}$ of age at first parturition. Separate residual variances were modeled for each of the age classes defined and no residual covariance was fitted. Convergence problems were encountered for this full model and for a reduced model, which divided the direct component into 4 traits while treating the maternal component as a single trait. Therefore, a number of further reduced versions of these models were tested to determine the optimal one. These reduced models constrained the covariances between the direct and maternal blocks of traits to zero and constrained the covariances within the direct and maternal blocks of traits to being all zero or all 0.99 .

\section{Random Regression Models}

Models were fitted with orthogonal polynomials for each sire and maternal grandsire, representing its EBV for the direct effect, on values of age at parturition and the dams of its progeny and grand-progeny, respectively. Models in which the maternal component was either partitioned into 4 traits or modeled using orthogonal polynomials failed to converge. Therefore, the maternal effect was included as a single effect:

$$
\begin{gathered}
y_{i j}=\mu+\text { fixed effects }+\sum_{t=0}^{n} D_{\text {sire }_{c}} \Phi_{t}\left(\text { Age }_{j}\right) \\
+\frac{1}{2} * \sum_{t=0}^{n} D_{m g s_{c}} \Phi_{t}\left(\text { Age }_{j}\right)+M_{m g s_{c}}+\frac{1}{2} * M_{m g s_{d}}+e_{i j},
\end{gathered}
$$

where $y_{i j}$ was a vector of transformed calving difficulty scores for each calf $i$ with a dam that calved at age $j$, $\mu$ was the overall mean, fixed effects were as for the previous models, and $D_{\text {sire }}$ and $D_{m g s_{c}}$ were random regression coefficients that were assumed to be normally distributed, with a mean of zero and a covariance matrix of order $n$. The values $\Phi_{t}\left(A g e_{j}\right)$ were the design values of the orthogonal Legendre polynomials $(t=0$ to $n$ ), where $t$ are the elements of the orthogonal polynomials, and $e_{i j}$ are the residuals. $M_{m g s_{c}}$ and $M_{m g s_{d}}$ were as for model 1. Convergence was attained when $a$ was equal to 1 and to 2 . A full version of this model was fitted that estimated all possible covariance components. In addition, for the purposes of comparison with previous models, a reduced version was fitted in which the genetic correlations between the direct and maternal effects were constrained to zero.

The described random regression models were fitted with both separate residual variances modeled for each of the age classes defined for the multitrait models and with a single residual variance component. For each model, the inverse of $\mathbf{A}$, the numerator relationship matrix, was calculated using sires, maternal grandsires, and sires of maternal granddams and where the 3 previous generations of ancestors of these ancestors were known. The pedigree contained 9,809 animals.

\section{Model Comparison}

To compare models, likelihood ratio tests (LRT), Akaike's information criteria (AIC), and Bayesian information criteria (BIC) were used. Akaike's information criteria and BIC were also chosen as LRT tend to favor models with many parameters (Jensen, 2001), whereas these criterion penalize models with many parameters. The likelihood ratio for 2 models $i$ and $j$, where $i$ is nested within $j$ was given by

$$
\mathrm{LRT}=2\left\lfloor\log \left(L_{i}\right)-\log \left(L_{j}\right)\right\rfloor \chi_{t_{i}-t_{j}}^{2},
$$

where $L_{i}$ and $L_{j}$ were the restricted log-likelihoods of the models to be compared and $t_{i}$ and $t_{j}$ were the corresponding number of parameters in those models. The difference between the function values of pairs of models can be tested against the degrees of freedom between the difference in number of variance or covariance components in the models. Significance was considered to be obtained at $P<0.05$. The AIC (Akaike, 1973) and BIC (Schwarz, 1978) were defined as

$$
\begin{aligned}
& \mathrm{AIC}=-2 \log \left(L_{i}\right)+2 t_{i}, \text { and } \\
& \mathrm{BIC}=-2 \log \left(L_{i}\right)+t_{i} \log v,
\end{aligned}
$$


Table 1. Percentage of records in category, and percentage of records receiving none, some, and severe assistance at calving and back-transformed mean (mean) for the total data set, for each sex, and for each of the 4 dam ages at parturition classes

\begin{tabular}{lcccrr}
\hline Item & Records, $\%$ & None, $\%$ & Some, $\%$ & Severe, $\%$ & Mean \\
\hline Total data & & 54.5 & 34.9 & 10.6 & 11.7 \\
Female & 52.1 & 61.0 & 31.8 & 7.2 & 9.8 \\
Male & 47.9 & 47.4 & 38.3 & 14.3 & 13.8 \\
Dam age, d & & & & & 11.5 \\
600-725 & 17.4 & 51.6 & 36.9 & 10.6 & 11.9 \\
$726-850$ & 46.8 & 53.7 & 35.8 & 9.5 & 10.7 \\
$851-975$ & 23.3 & 58.2 & 32.3 & 11.4 & 11.8 \\
$976-1,100$ & 12.5 & 54.7 & 33.9 & & \\
\hline
\end{tabular}

where $t_{i}$ was the number of variance parameters in model $i$ and $v=n-p$ was the number of residual degrees of freedom, where $n$ was the number of observations and $p$ was the number of estimable fixed effects in the model. The AIC and BIC were calculated for each model, and the model with the lowest value was assumed to be optimal.

\section{Calculation of Genetic Parameters}

Direct genetic variance $\left(\sigma_{\mathrm{d}}^{2}\right)$ was calculated by multiplying the estimated sire variance $\left(\sigma_{\mathrm{s}}^{2}\right)$ by 4 , and the maternal genetic variance $\left(\sigma_{\mathrm{m}}^{2}\right)$ was calculated by multiplying the estimated maternal grandsire variance $\left(\sigma_{\text {mgs }}^{2}\right)$ by 4 . The phenotypic variance $\left(\sigma_{\mathrm{p}}^{2}\right)$ was calculated as $1.25 \sigma_{\mathrm{s}}^{2}+1.25 \sigma_{\mathrm{mgs}}^{2}+\sigma_{\mathrm{r}}^{2}$, where $\sigma_{\mathrm{r}}^{2}$ was the estimated residual variance. The factor of 1.25 was used because effects for both sires (1.0 times the direct variance) and maternal grandsires ( 0.25 times the direct variance) explained part of the direct genetic variance, and both maternal grandsires ( 1 times the maternal variance) and sires of maternal grand-dams ( 0.25 times the maternal variance) explained part of the maternal genetic variance. Direct $\left(\mathrm{h}_{\mathrm{d}}^{2}\right)$ and maternal $\left(\mathrm{h}_{\mathrm{m}}^{2}\right)$ heritabilities $\left(\mathrm{h}^{2}\right)$ were calculated as $\sigma_{\mathrm{d}}^{2} / \sigma_{\mathrm{p}}^{2}$ and $\sigma_{\mathrm{m}}^{2} / \sigma_{\mathrm{p}}^{2}$, respectively.

\section{RESULTS}

\section{Data Summary}

The edited data set is summarized in Table 1 . In the final data set, $54.5 \%$ of calves born received no assistance at birth, $34.9 \%$ received some assistance, and $10 \%$ received serious assistance, whereas the backtransformed mean for serious assistance was $11.7 \%$. Twice as many males $(14.3 \%)$ as females $(7.2 \%)$ required serious assistance. The proportions of calves requiring serious assistance at birth were not different in the 4 age classes defined. Of the 2,341 contemporary groups, 628 , representing $54.2 \%$ of the data, contained more than 8 animals. A total of 999 sires and 980 mater- nal grandsires were represented in the data set. In addition, 446 sires were represented as maternal grandsires and $83 \%$ of the records were offspring of sires that had more than 10 offspring in the data set. Sires that had more than 50 offspring in the data set had offspring that made up $55 \%$ of the total records. These trends were similar in the case of the maternal grandsires.

Population average estimates of direct genetic, maternal genetic, and phenotypic variances, direct and maternal heritabilities, and the genetic correlation between direct and maternal effects are given in Table 2. The heritability was low for both the direct $(0.12)$ and maternal (0.04) traits and significantly different from zero. The estimated genetic correlation between the direct and maternal effects was moderately negative $(-0.47)$.

\section{Model Comparison}

Tables 3 and 4 contain the results of the model comparison. Comparisons using the LRT, AIC, and BIC showed that estimating the genetic correlation between the direct and maternal effects was superior to fixing it to zero. In the multitrait models, fixing the genetic correlations within the direct and maternal blocks of traits to 0.99 was more optimal than fixing them to zero. The multitrait model, which divided the maternal component into 4 traits, was not more optimal than the

Table 2. Population average phenotypic variance $\left(\sigma_{\mathrm{p}}^{2}\right)$, direct genetic variance $\left(\sigma_{\mathrm{d}}^{2}\right)$, maternal genetic variance $\left(\sigma_{\mathrm{m}}^{2}\right)$, direct heritability $\left(\mathrm{h}_{\mathrm{d}}^{2}\right)$, maternal heritability $\left(\mathrm{h}_{\mathrm{m}}^{2}\right)$, and genetic correlation $\left(\mathrm{r}_{\mathrm{dm}}\right)$ between the direct and maternal traits, with standard errors as subscripts

\begin{tabular}{lr}
\hline Parameter & Estimate \\
\hline$\sigma_{\mathrm{p}}^{2}$ & $0.95_{0.01}$ \\
$\sigma_{\mathrm{d}}^{2}$ & $0.12_{0.03}$ \\
$\sigma_{\mathrm{m}}^{2}$ & $0.04_{0.01}$ \\
$\mathrm{~h}_{\mathrm{d}}^{2}$ & $0.13_{0.03}$ \\
$\mathrm{~h}_{\mathrm{m}}^{2}$ & $0.04_{0.01}$ \\
$\mathrm{r}_{\mathrm{dm}}$ & $-0.47_{0.16}$ \\
\hline
\end{tabular}


Table 3. Univariate (UN), multitrait (MT), and random regression (RR) models fitted to the data with the total number of variance components estimated (VC), the number of variance components estimated for the direct $\left(\# \sigma_{\mathrm{d}}\right)$ and maternal $\left(\# \sigma_{\mathrm{m}}\right)$ components, the value $(0$ or 0.99$)$ to which the genetic correlations between the direct and maternal $\left(\mathrm{r}_{\mathrm{dm}}\right)$, direct and direct $\left(\mathrm{r}_{\mathrm{dd}}\right)$, and maternal and maternal $\left(\mathrm{r}_{\mathrm{mm}}\right)$ components were constrained or estimated (where $s$ was the correlation estimated from the data), the number of residual classes (\#res), Akaike's information criteria (AIC), and Bayesian information criteria (BIC) for each model

\begin{tabular}{lrcccccccc}
\hline Model & VC & $\# \sigma_{\mathrm{d}}$ & $\# \sigma_{\mathrm{m}}$ & $\mathrm{r}_{\mathrm{dm}}$ & $\mathrm{r}_{\mathrm{dd}}$ & $\mathrm{r}_{\mathrm{mm}}$ & $\#$ res & AIC & BIC \\
\hline UN & 4 & 1 & 1 & $s$ & & & 1 & $19,381.8$ & $19,390.7$ \\
UN & 3 & 1 & 1 & 0 & & & 1 & $19,384.9$ & $19,391.6$ \\
MT & 12 & 4 & 4 & 0 & 0 & 0 & 4 & $19,426.6$ & $19,453.2$ \\
MT & 12 & 4 & 4 & 0 & 0.99 & 0.99 & 4 & $19,396.6$ & $19,423.2$ \\
MT & 9 & 4 & 1 & 0 & 0 & & 4 & $19,433.5$ & $19,453.4$ \\
MT & 9 & 4 & 1 & 0 & 0.99 & & 4 & $19,386.1$ & $19,406.1$ \\
RR & 8 & 2 & 1 & $s$ & $s$ & & 4 & $19,376.1$ & $19,393.9$ \\
RR & 7 & 2 & 1 & 0 & $s$ & & 4 & $19,378.9$ & $19,394.4$ \\
RR & 9 & 3 & 1 & $s$ & $s$ & & 4 & $19,370.7$ & $19,390.6$ \\
RR & 8 & 3 & 1 & 0 & $s$ & & 4 & $19,375.2$ & $19,392.9$ \\
RR & 5 & 2 & 1 & $s$ & $s$ & & 1 & $19,371.7$ & $19,382.7$ \\
RR & 4 & 2 & 1 & 0 & $s$ & & 1 & $19,374.5$ & $19,383.4$ \\
RR & 6 & 3 & 1 & $s$ & $s$ & & 1 & $19,366.5$ & $19,379.8$ \\
RR & 5 & 3 & 1 & 0 & $s$ & & 1 & $19,371.1$ & $19,382.2$ \\
\hline
\end{tabular}

model that assumed it was a single trait according to the LRT, AIC, and BIC. According to the 3 comparison criteria, the second-order random regression models were superior to the first-order random regression models. The second-order random regression model, which fitted a single residual variance, was superior to that which allowed for heterogeneity of residual variance dependent on dam age according to the AIC and BIC but not the LRT. Overall, the model with a secondorder random regression for the direct component, which estimated the correlation between the direct and maternal components and estimated a single residual variance component, was optimal. The model comparisons suggest that there was significant heterogeneity

Table 4. Pairs of full and reduced models compared using likelihood ratio tests, with the $\mathrm{df}$ for each test

\begin{tabular}{|c|c|c|c|c|}
\hline Full model $^{1}$ & $\begin{array}{c}\text { Reduced } \\
\text { model }^{1}\end{array}$ & $\begin{array}{l}\text { Likelihood } \\
\text { ratio }\end{array}$ & $\mathrm{df}$ & Significance \\
\hline $\mathrm{UNr}_{\mathrm{dm}(\mathrm{s})}$ & $\mathrm{UNr}_{\mathrm{dm}(0)}$ & 5.2 & 1 & * \\
\hline $\mathrm{MTm}_{4}$ & $\mathrm{MTm}_{1}$ & 4.4 & 3 & NS \\
\hline $\mathrm{RR}_{1} \mathrm{e}_{4} \mathrm{r}_{\mathrm{dm}(\mathrm{s})}$ & $\mathrm{RR}_{1} \mathrm{e}_{4} \mathrm{r}_{\mathrm{dm}(0)}$ & 4.6 & 1 & $*$ \\
\hline $\mathrm{RR}_{2} \mathrm{e}_{4} \mathrm{r}_{\mathrm{dm}(\mathrm{s})}$ & $\mathrm{RR}_{2} \mathrm{e}_{4} \mathrm{r}_{\mathrm{dm}(0)}$ & 6.4 & 1 & ** \\
\hline $\mathrm{RR}_{1} \mathrm{e}_{1} \mathrm{r}_{\mathrm{dm}(\mathrm{s})}$ & $\mathrm{RR}_{1} \mathrm{e}_{1} \mathrm{r}_{\mathrm{dm}(0)}$ & 5.0 & 1 & $*$ \\
\hline $\mathrm{RR}_{2} \mathrm{e}_{1} \mathrm{r}_{\mathrm{dm}(\mathrm{s})}$ & $\mathrm{RR}_{2} \mathrm{e}_{1} \mathrm{r}_{\mathrm{dm}(0)}$ & 6.6 & 1 & $* *$ \\
\hline $\mathrm{RR}_{2} \mathrm{e}_{4} \mathrm{r}_{\mathrm{dm}(\mathrm{s})}$ & $\mathrm{RR}_{1} \mathrm{e}_{4} \mathrm{r}_{\mathrm{dm}(\mathrm{s})}$ & 7.4 & 1 & $* * *$ \\
\hline $\mathrm{RR}_{2} \mathrm{e}_{1} \mathrm{r}_{\mathrm{dm}(\mathrm{s})}$ & $\mathrm{RR}_{1} \mathrm{e}_{1} \mathrm{r}_{\mathrm{dm}(\mathrm{s})}$ & 7.0 & 1 & $* * *$ \\
\hline $\mathrm{RR}_{2} \mathrm{e}_{4} \mathrm{r}_{\mathrm{dm}(\mathrm{s})}$ & $\mathrm{RR}_{2} \mathrm{e}_{1} \mathrm{r}_{\mathrm{dm}(\mathrm{s})}$ & 1.8 & 3 & NS \\
\hline $\mathrm{RR}_{2} \mathrm{e}_{1} \mathrm{r}_{\mathrm{dm}(\mathrm{s})}$ & $\mathrm{UNr}_{\mathrm{dm}(\mathrm{s})}$ & 19.2 & 2 & $* * *$ \\
\hline $\mathrm{MTm}_{1}$ & $\mathrm{UNr}_{\mathrm{dm}(\mathrm{s})}$ & 1.2 & 5 & NS \\
\hline
\end{tabular}

${ }^{1} \mathrm{UN}=$ univariate model $; \mathrm{MT}=$ multitrait model with 4 direct components (all genetic correlations fixed to 0.99$), \mathrm{m}_{4}\left(\mathrm{~m}_{1}\right)=4$ (1) maternal components; $R_{1}\left(R_{2}\right)=$ first- (second-) order random regression on direct component, $\mathrm{e}_{4}\left(\mathrm{e}_{1}\right)=4(1)$ maternal components $=4$ (1) residual components; $\mathrm{r}_{\mathrm{dm}(\mathrm{s})}\left[\mathrm{r}_{\mathrm{dm}(0)}\right]=$ direct maternal correlation estimated (fixed to 0).

$* P<0.05 ; * * P<0.025 ; * * * P<0.01 ; \mathrm{NS}=P>0.05$. of variance for the direct component of calving difficulty, whereas the residual variance was homogeneous.

\section{Heterogeneity of Variance}

The estimates of direct genetic variance from the optimal random regression model were slightly higher than those from the optimal multitrait model shown in Table 4. Initially, there was a slight reduction in genetic variance followed by a steady increase in slope along the dam age trajectory. At the youngest dam age at calving, the random regression estimate of direct genetic variance was 0.19 units $^{2}$. This value decreased to a value of 0.11 units $^{2}$ at a dam age of $750 \mathrm{~d}$ and increased again to 0.38 units $^{2}$ at the oldest dam age. Because phenotypic variance was homogeneous, with a value of 1.05 units $^{2}$, the direct heritability of calving difficulty followed the same trend as observed for the direct genetic variance, that is, a slight initial reduction followed by an increase with increasing dam age at parturition (Figure 1). At the youngest dam age, direct heritability was 0.20 , which decreased to 0.11 before increasing to 0.37 at the oldest dam age. Maternal heritability was 0.04 . Although the standard errors of the multitrait estimates of direct genetic variance, shown in Table 5, suggested that no significant distinction could be made between the direct genetic variance across the dam age trajectory, the estimates themselves also reduced and then increased with dam age.

\section{Genetic Correlations}

The correlations declined from unity as the interval between dam ages increased. The first-order random regression estimates of the genetic correlations were 
Table 5. Direct $\left(\sigma_{\mathrm{d}}^{2}\right)$ genetic, maternal $\left(\sigma_{\mathrm{m}}^{2}\right)$ genetic, and phenotypic variance $\left(\sigma_{\mathrm{p}}^{2}\right)$, with $\mathrm{SE}$, for calving difficulty in the 4 defined dam age classes, estimated using the optimal multitrait model

\begin{tabular}{lcccccc}
\hline Dam age, d & $\sigma_{\mathrm{d}}^{2}$ & $\mathrm{SE}$ & $\sigma_{\mathrm{m}}^{2}$ & $\mathrm{SE}$ & $\sigma_{\mathrm{p}}^{2}$ & $\mathrm{SE}$ \\
\hline $600-725$ & 0.10 & 0.04 & & & 0.94 & 0.03 \\
$726-850$ & 0.10 & 0.02 & & & 0.93 & 0.02 \\
$851-975$ & 0.07 & 0.02 & & & 0.95 & 0.02 \\
$976-1,100$ & 0.16 & 0.05 & 0.03 & 0.01 & 0.94 & 0.03 \\
$600-1,100$ & & & 0.03 & & \\
\hline
\end{tabular}

all greater than 0.29 , whereas the lowest genetic correlation for the second-order random regression was 0.5 . Generally, the genetic correlations formed a flat plateau within certain age ranges. When dam age was low $(<760$ $\mathrm{d}$ of age at parturition), values for the genetic correlations between the direct effects were greater than 0.90 when the difference between dam ages at parturition were small $(<75 \mathrm{~d})$. The age range for the plateau widened to $200 \mathrm{~d}$ as the dam age increased to $1,100 \mathrm{~d}$.

Table 6 shows the correlations between the breeding values, estimated using the optimal random regression model, at the mean dam age at calving and at both 1 and 2 standard deviations on each side of the mean, for all 71 sires that had more than 50 offspring in the data set. As with the genetic correlations, the correlations between EBV decreased with increasing distance between dam ages. The correlation between EBV for sires at 2 standard deviations below and 2 standard deviations above the mean dam age at calving, 606 and $1,043 \mathrm{~d}$ of age, respectively, was 0.70 .

Figure 2 shows the genetic correlations between the direct effects for calving difficulty at specific dam ages and the maternal effect for calving difficulty modeled by the optimal random regression model. Estimates within 2 standard deviations of the mean dam age at calving ranged between -0.37 and -0.58 .

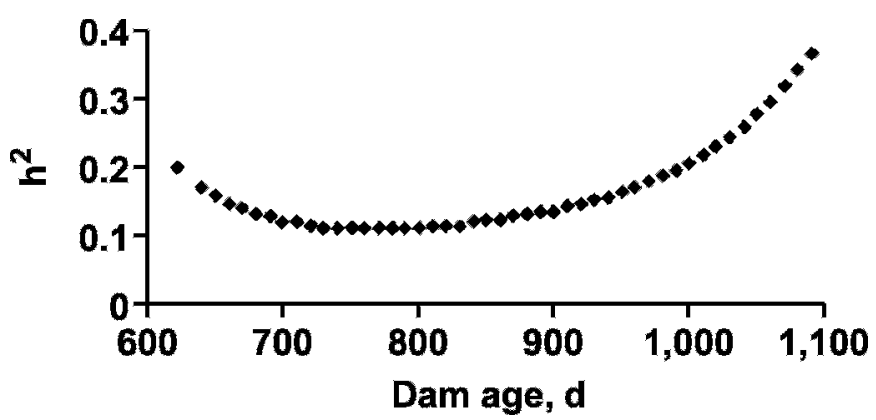

Figure 1. Estimated direct heritability $\left(h^{2}\right)$ for transformed calving difficulty scores, estimated across different dam ages at parturition using a model with a second-order random regression on the direct component.

\section{DISCUSSION}

Genetic parameters for calving difficulty were estimated using calving performance data collected routinely by Irish farmers. The direct genetic variance for calving difficulty displayed heterogeneity along dam age at the parturition trajectory, whereas the maternal genetic and phenotypic variance did not. The direct and maternal components of calving difficulty were shown to be negatively correlated. Although dam age at parturition has been shown to affect the incidence of calving difficulty in heifers in other studies (e.g., Berger et al., 1992), it did not affect it in this study. The gender differences in the incidence of calving difficulty in this data set may be attributable to a difference in shape as well as size. Male calves may be broader or have a heavier skeleton (Belic and Menissier, 1968, as cited in Meijering, 1986). However, variations in morphology independent of calf size (constant birth weight) are generally small compared with those of birth weight (Menissier and Foulley, 1979).

Population average heritabilities were low and were similar to values obtained in other studies. Steinbock et al. (2003) estimated direct and maternal heritabilities as 0.06 and 0.05 , respectively, on the visual scale, and as 0.19 and 0.15 , respectively, when the data were transformed to an underlying scale. Jamrozik et al. (1997), using a linear model, estimated these parameters as 0.08 and 0.14 , respectively. These results were all within the range ( 0.03 to 0.14 ) of heritability estimates for direct and maternal calving difficulty for Holstein heifers reported by other workers (Weller and

Table 6. Correlations between breeding values for the 71 sires with more than 50 offspring, estimated by the optimal random regression model at the mean dam age at calving ( $824 \mathrm{~d}$ of age), at 1 and 2 SD above and below the mean dam age, and between the estimates from the optimal univariate model

\begin{tabular}{llllll}
\hline Item & 606 & 715 & 824 & 934 & 1,043 \\
\hline 715 & 0.93 & & & & \\
824 & 0.79 & 0.95 & & & \\
934 & 0.72 & 0.88 & 0.96 & & \\
1,043 & 0.70 & 0.78 & 0.86 & 0.96 & \\
Univariate & 0.85 & 0.97 & 0.99 & 0.96 & 0.88 \\
\hline
\end{tabular}




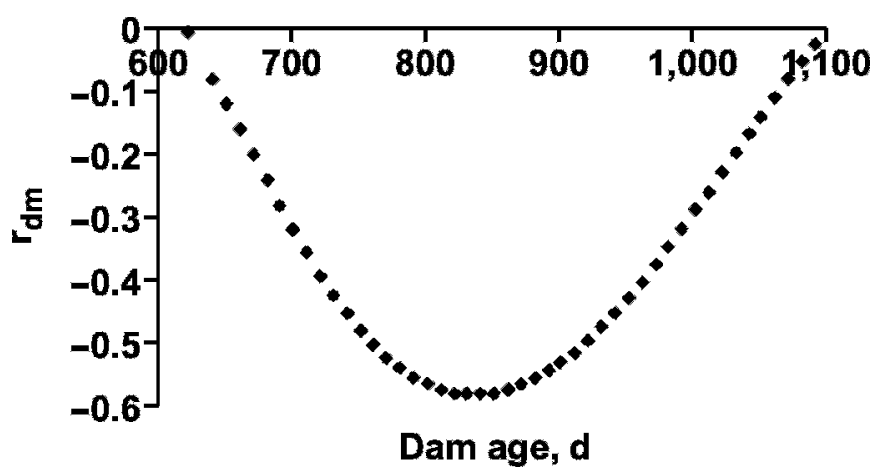

Figure 2. Genetic correlations $\left(\mathrm{r}_{\mathrm{dm}}\right)$ between direct and maternal effects for calving difficulty across different dam ages at parturition, estimated using a second-order random regression model on the direct component.

Gianola, 1989; Cue et al., 1990; Manfredi et al., 1991; Luo et al., 2002). The negative genetic correlation between direct and maternal effects found in the present study was consistent with other literature reports. Philipsson et al. (1979) suggested that female calves of a small size are likely to be born easily, but as adults they may experience more difficulties in giving birth because of the reduced pelvic opening dimensions. This is a plausible biological explanation for the negative genetic association between the direct and maternal components of calving difficulty. However, Meijering (1986) failed to find evidence to support this hypothesis and Naazie et al. (1991) found low genetic and phenotypic correlations between pelvic size of the dam and calving difficulty score.

The data used in this study provide estimates of direct and maternal heritability that were similar to estimates from other studies (e.g., Wiggans et al., 2003). This indicates that on-farm recording of calving performance in Ireland provides sufficient information for the estimation of genetic parameters and prediction of breeding values for calving difficulty for Irish Holstein heifers, despite the fact that $56.7 \%$ of the data were removed because of all calvings in a herd being recorded as having the same degree of difficulty. However, further extension work is required to ensure that these farmers sufficiently understand and use the scale for measuring calving difficulty.

\section{Model Comparison}

The 3 model comparison criteria suggested that estimating the genetic correlation between the direct and maternal components was optimal compared with fixing it to zero, and that significant heterogeneity of genetic (co)variance existed for the direct component but not the maternal component across the trajectory of dam age at calving. A random regression approach was superior to a multitrait approach to modeling such heterogeneity. In addition, the random regression model allowed the estimation of correlations across the direct component and between the direct and maternal components, which was not possible with the multitrait model. The effective improvement in accuracy of selection, when using a model that accounts for heterogeneity of variance compared with a model that ignores it, can be seen in Table 6 . This table shows the correlations between EBV for the direct components of calving ease from the optimal univariate model and the optimal random regression model for all 71 sires that had more than 50 offspring in the data set. At the mean dam age at calving, the EBV from both models were correlated to a value of 0.99 . However, for values of dam age at calving at 2 standard deviations above and below the mean, the correlations between estimates from both models were reduced to 0.88 and 0.85 , respectively. These correlations between breeding values estimated from the different models were observed despite the caution with which the genetic correlations between extreme ages estimated from the random regression models should be treated. Many authors have reported problems in modeling covariances between early and late records (e.g., Jamrozik et al., 1997; Pool and Meuwissen, 1999). A small number of records that are far from the mean and sampling variation in the partitioning of total variation, as well as overparameterization, have been pointed out as possible reasons for these problems (Meyer, 1999, 2000). This caution should be extended to the correlations between the direct and maternal components estimated from the random regression models. Although the direct (co)variances were consistent between the first- and second-order models and with those estimated from the multitrait model, the direct-maternal genetic correlations, although always negative, differed considerably between these models.

\section{(Co)variance Components}

Heterogeneity of genetic (co)variance for the direct, but not the maternal, component of calving difficulty was observed along the trajectory of dam age at parturition. Because there was no corresponding change in phenotypic variance, the heritability for the direct component followed the same trend. With an increasing difference between dam ages at parturition, the genetic correlations between the direct calving difficulty traits reduced to values that were considerably less than unity. This suggests that the genes controlling the direct effects of calving difficulty may be dependent on dam age. Reranking and rescaling of sires' EBV along the dam age trajectory occurred, which was consistent 


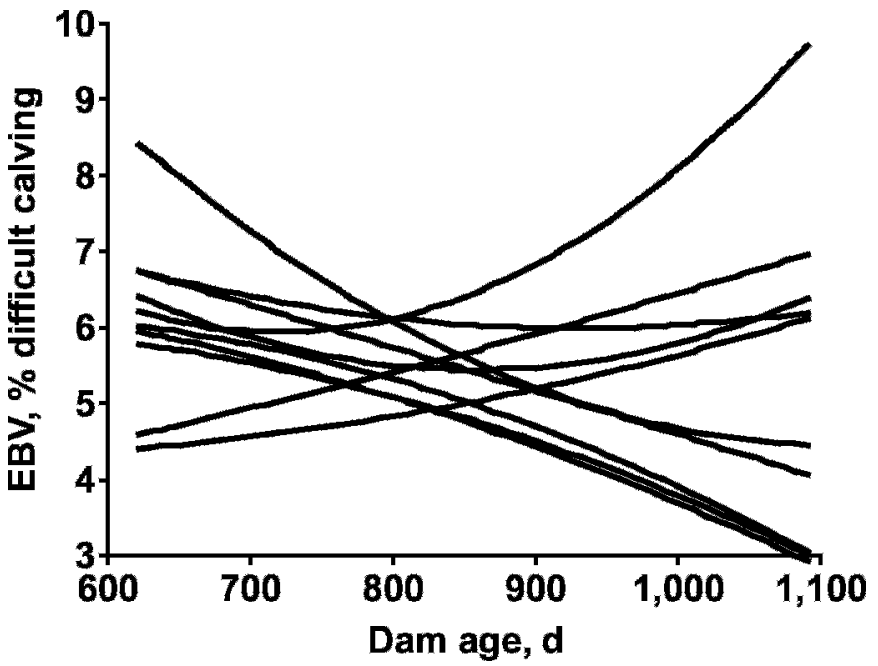

Figure 3. Back-transformed EBV for the direct component of calving difficulty for the 10 sires with the most offspring present in the data set, estimated using the optimal random regression model.

with expectations based on both the genetic correlations and on the correlations between the EBV for different dam ages at calving. This is displayed in Figure 3 for the 10 sires that had the largest number offspring in the data set. Each of these bulls had at least 266 offspring and had data represented across the entire dam age trajectory. Certain bulls performed relatively better when mated with younger heifers, whereas others were more suited to being mated with older heifers. Failure to take into account such heterogeneity may lead to inaccurate and biased predictions of breeding values (Visscher and Hill, 1992). Explaining such reranking is difficult, especially given that there were no differences in mean incidence across the dam age classes. Meijering (1986), in a review, concluded that birth weight of the calf and pelvic opening dimensions of the dam were traits with the greatest impact on calving difficulty in heifers. Thus, feto-pelvic incompatibility may be an explanation for reranking. A sire whose offspring are heavy at birth would be born with greater ease to older heifers than to younger ones. Similarly, a bull with a propensity to produce malpresented offspring at birth could have poorer performance with younger, smaller heifers than with older, larger ones. Osinga (1978) reported that secretion of estrogenic hormones by the fetal membranes might be related to dystocia. Maternal preparation for parturition might then come under the influence of fetal genotype. It could be speculated that fetal hormone production is affected by or affects hormone levels in the dam. Hormone levels in the dam could be affected by her age. However, a random regression model approach to estimating breed- ing values may be necessary only when selecting sires to be mated to heifers of extreme ages.

\section{CONCLUSIONS}

The data on calving difficulty recorded by farmers in Ireland is collected with sufficient precision to allow the estimation of genetic parameters for calving difficulty. Further extension work is required to ensure that all Irish farmers sufficiently understand and use the scale of measuring calving difficulty. The direct and maternal heritabilities were low for calving difficulty. These 2 components were moderately genetically antagonistic. There was heterogeneity of direct genetic variance depending on the age of the dam at parturition. In situations in which there are large differences in heifer ages at first parturition, accounting for such heterogeneity would enhance genetic evaluations.

\section{ACKNOWLEDGMENTS}

The authors acknowledge the useful discussions with Mario Calus and Marco Pool of Animal Sciences Group, and Donagh Berry of Teagasc, Moorepark. The Irish Cattle Breeding Federation is acknowledged for providing the data.

\section{REFERENCES}

Akaike, H. 1973. Information theory and an extension of the maximum likelihood principle. Pages 267-281 in 2nd Int. Symp. Inf. Theory. Academiai Kiado, Budapest, Hungary.

Arango, J. A., L. V. Cundiff, and L. D. Van Vleck. 2004. Covariance functions and random regression models for cow weight in beef cattle. J. Anim. Sci. 82:54-67.

Belic, M., and F. Menissier. 1968. Etude de quelques facteurs influençant les difficultés de vêlage en croisement industriel. Ann. Zootech. 17:107-142.

Bennett, G. L., and K. E. Gregory. 2001. Genetic (co)variances for calving difficulty score in composite and parental populations of beef cattle: I. Calving difficulty score, birth weight, weaning weight, and postweaning gain. J. Anim. Sci. 79:45-51.

Berger, P. J., A. C. Cubas, K. J. Koehler, and M. H. Healey. 1992. Factors affecting dystocia and early calf mortality in Angus cows and heifers. J. Anim. Sci. 70:1775-1786.

Calus, M. P. L., and R. F. Veerkamp. 2003. Estimation of environmental sensitivity of genetic merit for milk production traits using a random regression model. J. Dairy Sci. 86:3756-3764.

Crump, R. E., N. R. Wray, R. Thompson, and G. Simm. 1997. Assigning pedigree beef performance records to contemporary groups taking account of within-herd calving patterns. Anim. Sci. 65:193-198.

Cue, R. I., H. G. Monardes, and J. F. Hayes. 1990. Relationships of calving ease with type traits. J. Dairy Sci. 73:3586-3590.

Dekkers, J. C. M. 1994. Optimal breeding strategies for calving ease. J. Dairy Sci. 77:3441-3453.

Gilmour, A. R., B. R. Cullis, S. J. Welham, and R. Thompson. 2006. ASReml User Guide (Release 2.0). VSN International Ltd., Hemel Hempstead, UK.

Groen, A. F., J. P. J. M. Van Aubel, and A. A. Hulzebosch. 1998. Calving performance in dairy cattle-Influence of maturity of dam on the correlation between direct and indirect effects. Pages 387-390 in Proc. 6th World Congr. Genet. Appl. to Livest. Prod., 
Armidale, Australia. Animal Breeding and Genetics Unit, University of New England, ed. AGBU, Armidale, Australia.

Jamrozik, J., L. R. Schaeffer, and J. C. M. Dekkers. 1997. Genetic evaluation of dairy cattle using test day yields and random regression model. J. Dairy Sci. 80:1217-1226.

Jensen, J. 2001. Genetic evaluation of dairy cattle using test-day models. J. Dairy Sci. 84:2803-2812.

Luo, M. F., P. J. Boettcher, L. R. Schaeffer, and J. C. M. Dekkers, 2002. Estimation of genetic parameters of calving ease in first and second parities of Canadian Holsteins using Bayesian methods. Livest. Prod. Sci. 74:175-184.

Manfredi, E., V. Ducrocq, and J. L. Foulley. 1991. Genetic analysis of dystocia in dairy cattle. J. Dairy Sci. 74:1715-1723.

Meijering, A. 1986. Dystocia in Dairy Cattle Breeding. Wageningen University, Wageningen, the Netherlands.

Menissier, F., and J. L. Foulley. 1979. Present situation of calving problems in the E.E.C.: Incidence of calving difficulties and early mortality in beef herds. Pages 30-85 in Calving Problems and Early Viability of the Calf. B. Hoffman, I. L. Mason, and J. Schmidt, ed. Martinus Nijhoff, the Hague, the Netherlands.

Meyer, K. 1999. Estimates of genetic and phenotypic covariance functions for postweaning growth and mature weight of beef cows. J. Anim. Breed. Genet. 116:181-205.

Meyer, K. 2000. Random regressions to model phenotypic variation in monthly weights of Australian beef cows. Livest. Prod. Sci. 65:19-38.

Misztal, I., D. Gianola, and J. L. Foulley. 1989. Computing aspects of a nonlinear method of sire evaluation for categorical data. J. Dairy Sci. 72:1557-1568.

Naazie, A., M. Makarechian, and R. T. Berg. 1991. Genetic, phenotypic, and environmental parameter estimates of calving diffi- culty, weight, and measures of pelvic size in beef heifers. J. Anim. Sci. 69:4793-4800.

Olori, V. E., P. Donnellan, A. R. Cromie, P. R. Amer, and R. F. Veerkamp. 2005. Availability and suitability of data for genetic evaluations of calving difficulty across cattle breeds in Ireland. Page 13 in Proc. Agric Res. Forum, Tullamore, Co. Offaly, Ireland. M. G. Diskin, ed. Standard Printers, Galway, Ireland.

Osinga, A. 1978. Endocrine aspects of bovine dystocia with special reference to estrogens. Theriogenology 10:149-166.

Philipsson, J., J. L. Foulley, J. Lederer, T. Liboriussen, and A. Osinga. 1979. Sire evaluation standards and breeding strategies for limiting dystocia and stillbirth. Livest. Prod. Sci. 6:111-127.

Pool, M. H., and T. H. E. Meuwissen. 1999. Prediction of daily milk yields form a limited number of test days using test-day models. J. Dairy Sci. 82:1555-1564.

Schmitz, F., R. W. Everett, and R. L. Quaas. 1991. Herd-year-season clustering. J. Dairy Sci. 74:629-636.

Schwarz, G. 1978. Estimating the dimension of a model. Ann. Statist. 6:461-464.

Steinbock, L., A. Nasholm, B. Berglund, K. Johansson, and J. Philipsson. 2003. Genetic effects on stillbirth and calving difficulty in Swedish Holsteins at first and second calving. J. Dairy Sci. $86: 2228-2235$

Visscher, P. M., and W. G. Hill. 1992. Heterogeneity of variance and dairy-cattle breeding. Anim. Prod. 55:321-329.

Weller, J. I., and D. Gianola. 1989. Models for genetic analysis of dystocia and calf mortality. J. Dairy Sci. 72:2633-2643.

Weller, J. I., and M. Ron. 1992. Genetic analysis of fertility traits in Israeli Holsteins by linear and threshold models. J. Dairy Sci. 75:2541-2548.

Wiggans, G. R., I. Misztal, and C. P. Van Tassell. 2003. Calving ease (co)variance components for a sire-maternal grandsire threshold model. J. Dairy Sci. 86:1845-1848. 